International Journal of Osteoarchaeology

Int. J. Osteoarchaeol. 17: 596-607 (2007)

Published online 12 April 2007 in Wiley InterScience

(www.interscience.wiley.com) DOI: 10.1002/oa.910

\title{
Identifying Artificially Deformed Crania
}

\author{
J. L. CLARK, ${ }^{a *}$ S. D. DOBSON, ${ }^{\text {b }}$ S. C. ANTÓN, ${ }^{c}$ J. HAWKS, ${ }^{d}$ \\ K. L. HUNLEY ${ }^{\mathbf{e}}$ AND M. H. WOLPOFF \\ a Museum of Anthropology, University of Michigan, Ann Arbor, MI 48109-1079, USA \\ ${ }^{b}$ Department of Anthropology, Dartmouth College, Hanover, NH 03775, USA \\ c Center for the Study of Human Origins, Department of Anthropology, \\ New York University, New York, NY 10003, USA \\ d Department of Anthropology, University of Wisconsin-Madison, Madison, WI 53706, USA \\ e Department of Anthropology, University of New Mexico, Albuquerque, NM 87131, USA \\ ${ }^{\dagger}$ Department of Anthropology, University of Michigan, Ann Arbor, MI 48109, USA
}

\begin{abstract}
In this paper we report on a new discriminant function for the identification of artificially deformed crania. Development of the function, based on a sample of deformed and undeformed crania from the Philippines, required visual classification of the sample into deformed and undeformed groups. Working from the observation that deformed crania display flattened frontal and occipital regions, the sample was seriated based on degree of flattening; classification was based on the results of this seriation. The discriminant function, calculated using curvature indices, required only six simple measurements: arc and chord measurements for the frontal (glabella to bregma), parietals (bregma to lambda) and occipital (lambda to opisthion). The function was designed to be conservative, in that a deformed cranium may be classified as undeformed, but the opposite should not occur. Our function classified the undeformed crania with 100\% accuracy and deformed crania with $76.9 \%$ accuracy, for a total of $91.9 \%$ agreement with visual classification. In order to evaluate whether the function is applicable for samples from outside the Philippines, a double blind test was conducted with a large sample of deformed and undeformed crania from a broad geographical and temporal range. For this sample, the function agreed with visual classification in $89.7 \%$ of cases; $98.8 \%$ of undeformed crania were correctly classified, while deformed crania were identified with $73.7 \%$ accuracy. These results demonstrate the utility of the new discriminant function for the classification of artificially deformed crania from diverse contexts.

Copyright (c) 2007 John Wiley \& Sons, Ltd.
\end{abstract}

Key words: artificial cranial deformation; discriminant function analysis; Guthe collection

\section{Introduction}

The practice of artificial cranial deformation has been documented on nearly every continent and may have been undertaken as early as 15,000 years ago (Dingwall, 1931; Brown, 1981; Antón \& Weinstein, 1999). Ethnographic accounts indicate that a myriad of cultures considered a

\footnotetext{
* Correspondence to: Museum of Anthropology, 4013 Musuems Building, University of Michigan, Ann Arbor, MI 48109-1079, USA. e-mail: jamielc@umich.edu
}

deformed head to be a mark of beauty, from the Songish of British Columbia, where those who had not been subjected to deformation practices were considered 'ill looking' (Boas, 1891, cited in Cheverud et al., 1992), to the Arawe of Melanesia, amongst whom a 'long head' was considered to be attractive to the opposite sex (Blackwood \& Danby, 1955). In addition, the practice of artificial cranial deformation has often been linked with elevated social standing (Ortner, 2003). As a form of bodily decoration used to mark group membership, artificial deformation 
serves as a significant cultural artefact (Dingwall, 1931; Gerszten, 1993). Unlike other forms of personal ornamentation such as tattooing, clothing style, or piercing, artificial deformation has a longer archaeological persistence, and thus the practice is of interest to archaeologists for its potential use in reconstructing aspects of past social systems. Furthermore, it is generally agreed that the distribution of cranial deformation, both within and between populations, may provide information on prehistoric population movement, ethnic identity, and social stratification (e.g. Hoshower et al., 1995).

Interest in cranial deformation is not only archaeological, however. Physical anthropologists have focused on the effects of deformation on craniofacial morphology and its influence on the occurrence of non-metric traits such as wormian bones (e.g. Antón et al., 1992; Cheverud et al., 1992; Freiss \& Baylac, 2003; O'Loughlin, 2004). There is also a place for the study of cranial deformation within palaeoanthropology: Trinkaus (1982: 199) argued that Shanidar 1 and 5 had been artificially deformed, suggesting that Neandertals had a 'behavioral pattern allied with that of early anatomically modern humans.' Furthermore, Antón \& Weinstein (1999) argued that the 'archaic' characteristics seen among certain early Australian crania were a result of cranial deformation and were therefore not a sign of genetic relatedness between fossil Australians and Indonesian Homo erectus (see Brown, 1981, for further discussion of the deformation status of Pleistocene Australian crania). Despite the importance of cranial deformation to so many issues of anthropological interest, the methods used by various scholars to identify crania as deformed can be highly subjective and often go unpublished, highlighting the need for more standardised methodology for the identification of artificially deformed crania.

Artificial (also known as intentional) cranial deformation results from manual manipulation of the skull and/or from the application of deforming apparatus and is manifested in morphological changes to the cranial vault, often involving flattening of the frontal and occipital regions (Antón \& Weinstein, 1999). Deformation can also be unintentional, as when the rear of the skull is flattened through the use of a cradleboard or because an infant frequently sleeps on a hard surface. For both types, deformation occurs most readily in the early stages of life when the cranial bones are more malleable. Ethnographic and ethnohistorical sources indicate that the practice of artificial deformation often begins within the first few days of birth, with apparatus being applied for an average of six months to one year (O'Loughlin, 2004).

Although artificial deformation can take many forms - Gerszten (1993) discussed as many as 14 unique cranial shapes resulting from various methods of deformation - the two most commonly described types are annular and fronto-occipital deformation. Annular (also known as circumferential) deformation occurs when the cranial vault is encircled in material such as bandages or tree bark. This compresses the cranium cylindrically, limiting growth mediolaterally but allowing for compensatory posterior and superior growth (Antón, 1989; Antón \& Weinstein, 1999). This results in increased cranial length and decreased breadth, causing these crania to appear ovoid in superior view. Fronto-occipital (or antero-posterior) deformation occurs when the frontal and occipital regions of the skull are bound with pads, boards or stones. This anteroposterior compression constricts growth between the frontal and occipital, with compensatory growth of the parietals in a mediolateral direction (Cheverud et al., 1992; White, 1996). Fronto-occipital deformation is characterised by decreased cranial length and increased cranial breadth, and is expressed by flattening of the frontal and occipital bones and occasionally by lateral bulging of the parietals (Antón, 1989).

The first step in any analysis involving deformed crania involves classification of a given sample into deformed and undeformed groups. However, there is often disagreement as to how best to define deformed crania, especially if the sample is from a single population that shows a continuum from non-deformed to highly deformed crania (Trinkaus, 1982). This means that the visual classification of a specific cranium as being intentionally modified must to some extent be subjective. The development of discriminant functions to assist in the classification of ambiguous crania is not uncommon,

Int. J. Osteoarchaeol. 17: 596-607 (2007)

DOI: $10.1002 /$ oa 
although Dean (1995) argued that such functions do not resolve the problems of subjectivity, as they require the researcher to first visually inspect the skulls, placing them in a priori deformed and undeformed groups; these groups are then used to evaluate the efficacy of a given function. In its own way, however, this is also a strength, as a function that does not agree with the visual classification of unambiguous crania is unlikely to provide any assistance in the classification of less obvious specimens. While the number and nature of measurements required for the application of discriminant functions may also restrict their utility, the stance taken here is that the appropriate function can assist in the confirmation of visual classification and in the categorisation of ambiguous specimens. Given the seemingly universal effects of artificial deformation on vault contours (Antón \& Weinstein, 1999), we sought to develop a discriminant function that used curvature indices as a proxy for degree of flattening of the frontal, parietals and occipital. This paper reports on the procedures involved in the development of this function and documents its utility in identifying artificially deformed crania.

\section{Materials}

The sample, which comprises 68 complete and nearly complete crania, derives from the University of Michigan Philippine Expedition, directed by Carl E. Guthe from 1922 to 1925. The goal of the expedition was to locate and excavate archaeological sites in the central and southern Philippines, including the Visayan group, Mindanao, Palawan, and the Sulu Archipelago (Guthe, 1929). Although the method of investigation was primarily exploratory, the collection comprises more than 13000 objects and associated documentation from 542 archaeological sites (Guthe, 1927). Of particular interest are the $\sim 20$ sites from which the crania that form the basis for this study were recovered, the majority of which were burial caves (Figure 1). These sites span a range of dates, with a majority of Asian trade-wares dating from the $14^{\text {th }}$ to $16^{\text {th }}$ centuries (Bacus, 1995).

Copyright (C) 2007 John Wiley \& Sons, Ltd.
The current sample was limited to adult and young adult specimens. Given that the determination of sex can be confounded by artificial deformation, and because the sample lacked associated post-cranial parts, the sample was not sexed. Finally, investigation was restricted to those crania from a single archaeological context (burial caves), and specimens showing clear pathological changes and/or significant post-depositional damage were removed from analysis.

\section{Methods}

\section{Visual classification}

The first step in the discriminant analysis involved visual classification of the sample. Based on previous work (cf. Friess \& Baylac, 2003), it was expected that variation between deformed and undeformed crania would be continuous and gradual. Therefore, in order to assist in categorisation, the sample was physically seriated on a two-dimensional grid that had been laid out upon several large laboratory tables. The seriation was based on degree of frontal and occipital flattening, with occipital flattening scaled along the $x$-axis and frontal flattening scaled on the $y$-axis. This meant that undeformed crania (those with round frontals and occipitals) would cluster in the top left corner of the grid, while artificially deformed crania (with flattened frontals and occipitals) would be located in the bottom right corner. Once the seriation was established, we continued to correct the position of crania over the course of several weeks until we were satisfied with the placement of the specimens. This process was completed twice (by different combinations of the authors), and while the results of the two seriation attempts were very similar, the function described here is based on the second seriation, primarily the work of the first author. The seriation was expected to result in a linear arrangement of crania along a single axis from round/round to flat/flat; however, a number of crania clustered in the lower left corner of the grid, showing occipital flattening but no discernable frontal flattening. Only one cranium was located in the upper right corner of the grid

Int. J. Osteoarchaeol. 17: 596-607 (2007)

DOI: $10.1002 /$ oa 


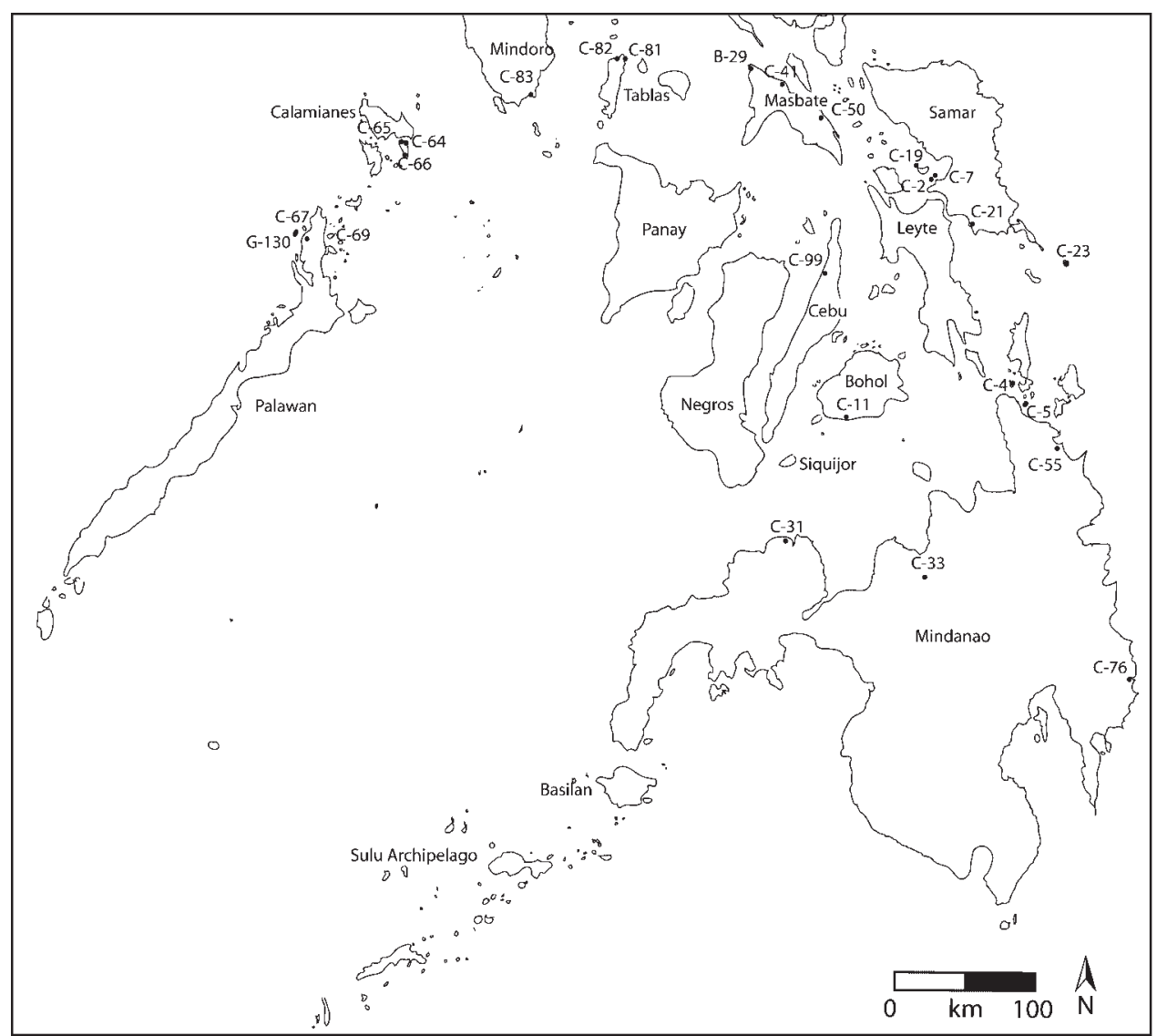

Figure 1. Map of the Central and Southern Philippines showing sites from the University of Michigan Philippine Expedition from which crania were recovered.

(flat frontal/round occipital); because this specimen was also morphologically distinct compared with the rest of the sample, it was removed from analysis. Seriated crania were thus divided into four categories: undeformed $(n=24)$; artificially deformed $(n=17)$; round frontal/flat occipital $(n=16) ;$ and ambiguous deformation status $(n=11)$ (Figure 2).

The largest category comprised undeformed crania. These specimens are predominantly characterised by rounded frontal and occipital regions (Figure 3). Some of the crania do show minimal frontal or occipital flattening, but not beyond what was determined to be within the realm of normal variation. In this case, 'normal variation' was defined based on the consideration of a cranial sample in which deformation was absent, which allowed for a recognition of the range of individual variation to be expected among normal crania in terms of cranial shape and the degree of frontal and occipital flattening.

Artificially deformed crania were identified based on the presence of significantly flattened frontal and occipitals, and are often associated with lateral bulging of the parietals near the lambdoid suture (Figure 4). However, the deformed group shows a great deal of variability. Some deformed crania have low and sloping frontals, while others are flattened with a more vertical profile. Parietal variation exists on two levels; firstly, some specimens show a great deal of curvature at the most superior aspect of the skull, while others are relatively flat. Furthermore, some crania show lateral bulging at the rear of the skull, resulting in a more triangular shape in superior view, while others do not display this trait and appear much more rounded. Although Antón 


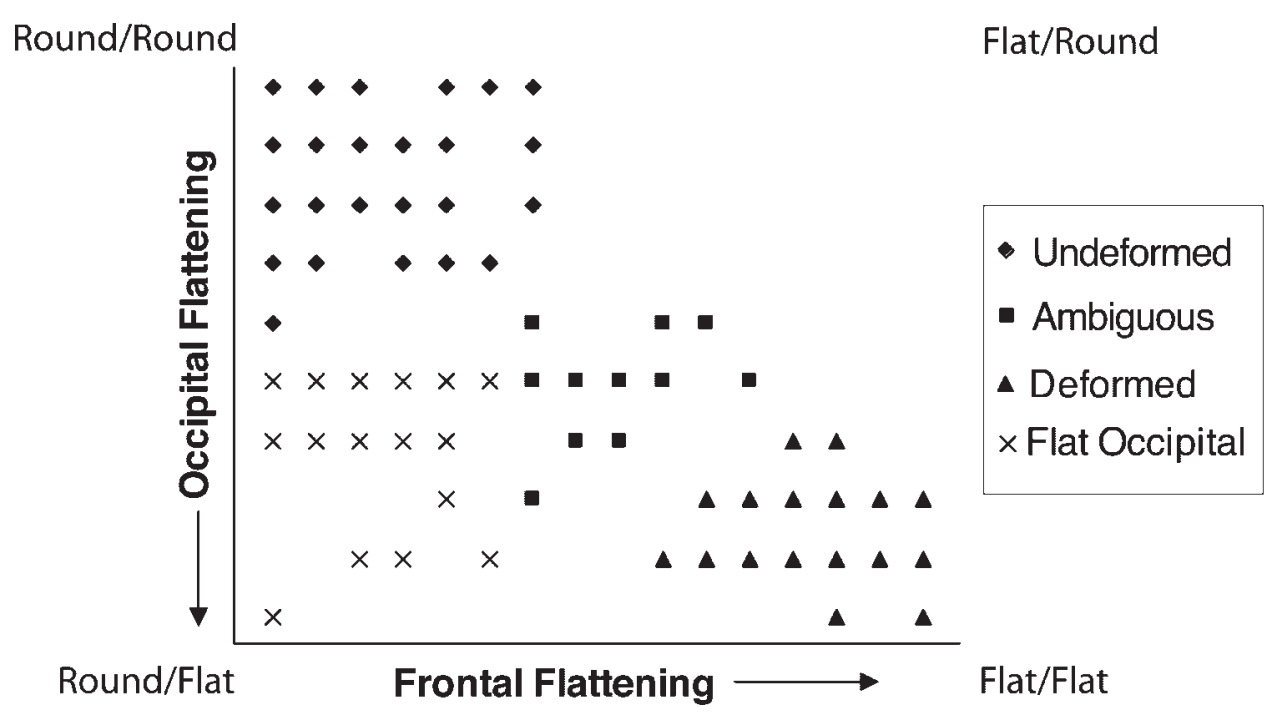

Figure 2. Results of seriation.

(1989) and White (1996) both associate fronto-occipital deformation with bilobed parietals (particularly evident in superior view), the feature is only present in one Philippine specimen. It is possible that the marked bilobial appearance of some fronto-occipitally deformed crania was due to the application of bandages and/or binding that created a depression along the sagittal suture, and that this practice was not common in the Philippines. However, it may also be the case that differences in developmental factors explain the lack of bilobed parietals in this sample. Finally, there was variability in occipital flattening, with some crania showing vertically oriented flattening at lambda and others showing more oblique nuchal flattening. All of the deformed crania

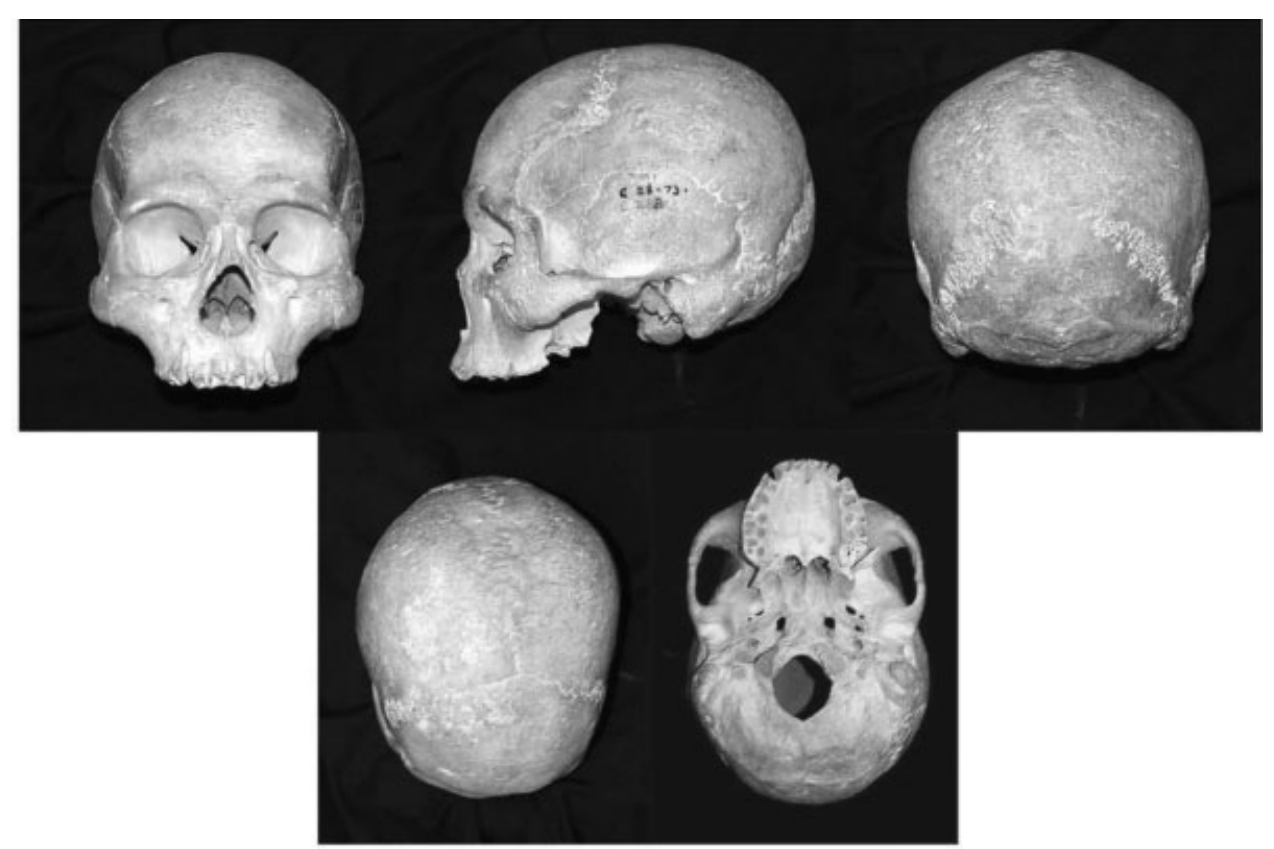

Figure 3. Undeformed cranium, C23.73T.

Copyright (C) 2007 John Wiley \& Sons, Ltd.

Int. J. Osteoarchaeol. 17: 596-607 (2007)

DOI: $10.1002 / \mathrm{oa}$ 



Figure 4. Deformed crania. From top left: lateral views of C23.73B, C23.73M, C23.73L, C24.24C, C23.73Q. Second row: alternative views of C23.73L.

represent fronto-occipital deformation. This deformation appears to be a result of the application of boards or stones strapped to the front and back of the skull; the observed variation may be a result of differential duration of application or of variability in the angle at which the deforming apparatus were bound to the skull.

The 16 crania characterised by round frontals but flattened occipitals were placed in a class of their own. This subset of the sample was not classified as artificially deformed due to the lack of evidence for involvement of the frontal (Figure 5). The deformation most likely resulted from cradleboarding, although ethnohistorical accounts documenting the practice of cradleboarding in the Philippines were not found. The crania show moderate to pronounced flattening of the occipital - this flattening occurs in both the nuchal region and around lambda. Watson (1999) suggested that both result from cradleboarding, but that lambdoidal flattening is caused by the use of a neck roll, which changes the angle of contact between the rear of the skull and the cradleboard so that the lambdoidal region would have been in contact with the hard surface. The occipital flattening is often asymmetrical ${ }_{i}$ this asymmetrical flattening was not limited to a single

Copyright (C) 2007 John Wiley \& Sons, Ltd. side but was noted on both the left and right sides.

The final 11 crania were not easily categorised as either normal or deformed. Morphology in this group is variable, although all show at least some degree of frontal and occipital flattening (Figure 6). Four of the 11 crania show a saddle-shaped depression immediately posterior to bregma. This is of interest because a number of scholars have linked these zonal depressions with deformation (Goldstein, 1940; Brown, 1981). Within the Philippine sample, however, the feature is present on only one clearly deformed cranium, and it is also found on two otherwise normal skulls. In an analysis that included more than 500 deformed and undeformed crania, Antón \& Weinstein (1999) noted that post-bregmatic depressions were consistently more frequent in deformed than undeformed crania. However, post-bregmatic depressions can occur with sufficient frequency in undeformed crania to be useful as a non-metric trait in forensic anthropological estimates of ancestry, with individuals of African ancestry more frequently possessing the trait (e.g. Gill, 1998). Therefore, the presence of the depressions, while notable, was not convincing enough evidence to place these crania into the deformed category. 


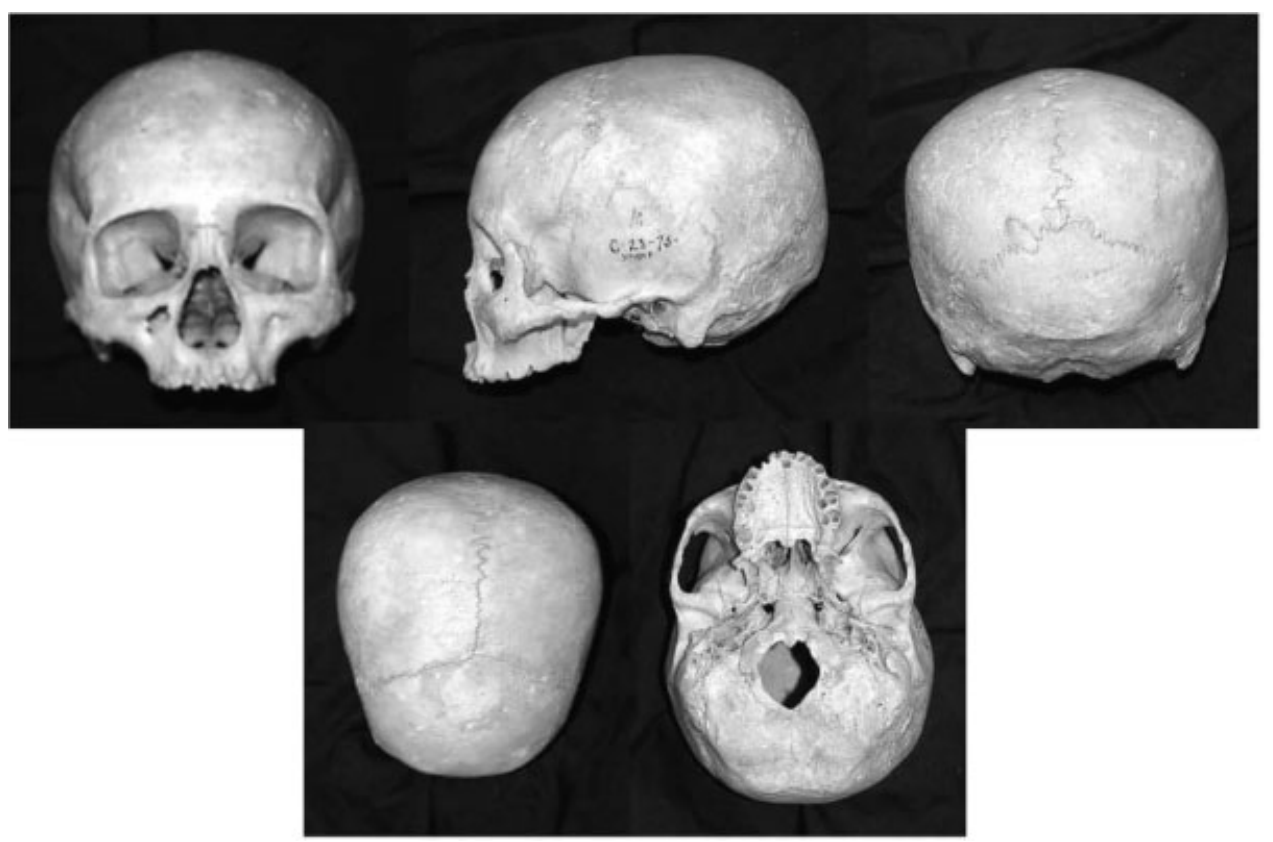

Figure 5. Round frontal/flat occipital, C23.73P.

Discriminant analysis

Although there has long been agreement that artificial deformation results in flattening of the frontal and occipital regions as compared with undeformed crania (e.g. Moss, 1958; Cheverud et al., 1992), Antón \& Weinstein (1999) were the first to conduct a systematic analysis of the effects of artificial deformation on vault contours across populations and deformation types (while analyses of a similar scope have taken place, these have often focused on such issues as the

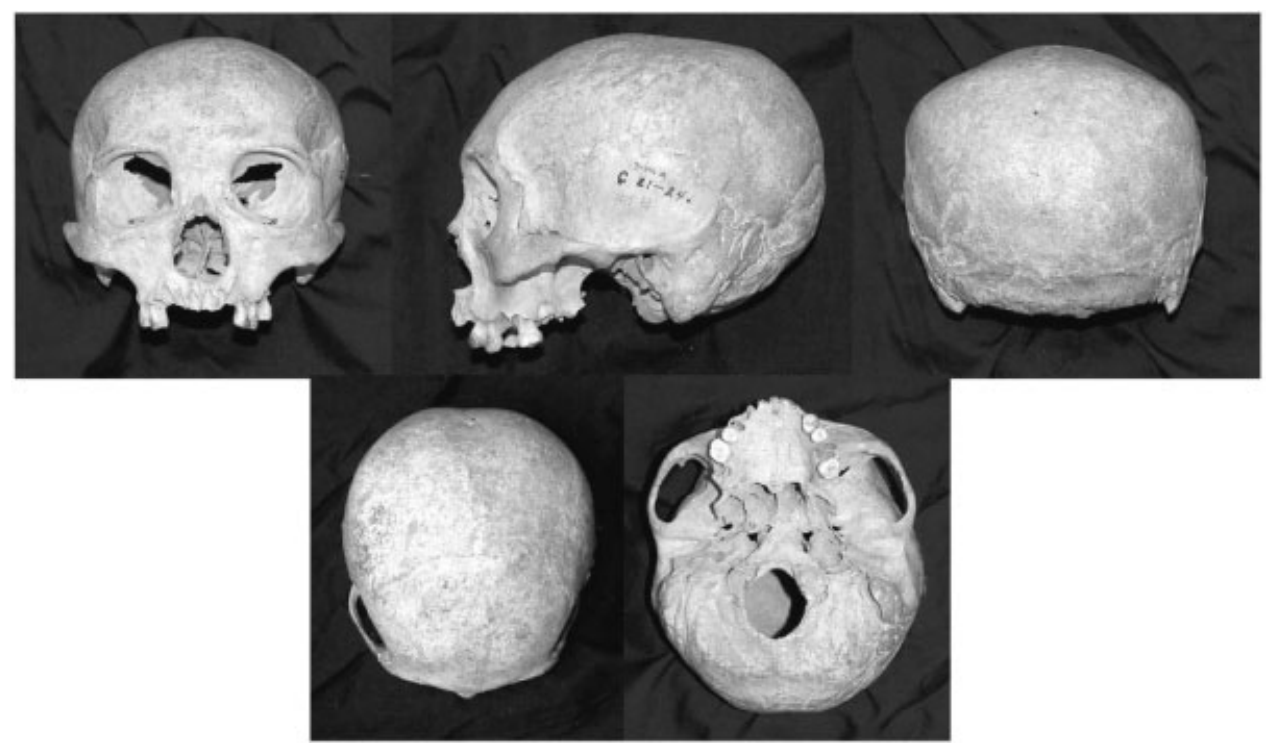

Figure 6. Ambiguous deformation status, C21.24A.

Copyright (C) 2007 John Wiley \& Sons, Ltd. 
effects of deformation on determinations of biological distance rather than on vault contours per se). Working from a sample of 588 crania that included deformed and undeformed specimens from North and South America and undeformed crania from Australia and New Zealand, Antón \& Weinstein (1999) demonstrated that both of the major types of deformation result in flattened frontals and occipitals, and that furthermore, these crania often show more angulated parietal regions. Given that the effects of artificial deformation on vault contours are seemingly universal, curvature indices for the frontal, parietal and occipital were chosen as the discriminating variables for our discriminant analysis.

Arc and chord measurements were taken along the sagittal plane from glabella to bregma (frontal), from bregma to lambda (parietal) and from lambda to opisthion (occipital). Arcs were taken by placing a plastic tape between each set of points, while chords were measured using Mitutoyo digital sliding calipers. The resolution of the tape allowed measurements to be taken only to the nearest millimetre; for the sake of consistency, measurements taken with the calipers (resolution $0.1 \mathrm{~mm}$ ) were rounded up or down before recording. For the frontal measurements, glabella was chosen over nasion because we were interested in the degree of frontal flattening - arc measurements taken from nasion are less informative as a result of variability in the projection of the supraorbital torus. Curvature indices were then calculated as (arc/chord) ${ }^{*} 100$. These indices serve as a proxy for degree of flattening, in that the closer the arc and chord measurements are to each other, the lower the index score, indicating a greater degree of flattening. A key benefit of using these indices is ease of measurement - the landmarks employed are easily identified, reducing the likelihood of inter-observer error.

Of the 68 crania subjected to visual classification, seven were removed from the analysis due to extensive damage to the cranial base. In addition, six of the 61 crania for which measurements were taken displayed some damage to the cranial base, although in these cases it was possible to reconstruct opisthion using modelling clay. Discriminant analysis was based upon only

Copyright (C) 2007 John Wiley \& Sons, Ltd. the unambiguously deformed and undeformed crania; this sample comprised 24 undeformed crania and 13 deformed crania.

\section{Results}

After collecting all the measurements and calculating the indices, data for the 37 unambiguously deformed and undeformed crania were entered into SPSS for the calculation of the following discriminant function:

$\left(-0.50337^{*}\right.$ frontal index $)+\left(0.43922^{*}\right.$ parietal index $)$

$-\left(0.49494^{*}\right.$ occipital index $)+59.302$

The constant (59.302) has been set so that the section point for classification is 0 . Thus, for this function, crania with negative scores are classified as undeformed and those with positive scores are classified as deformed. This reflects the fact that undeformed crania will have rounded frontals and occipitals, meaning they will have higher index scores for these elements. Since the frontal and occipital indices are multiplied by negative coefficients, the total function score will be more negative. Alternatively, since deformed crania have flattened frontal and occipital bones, they will show lower index scores, resulting in a more positive function score. The constant was also set in such a way that no crania that were visually classified as undeformed received a positive function score. This means that the function is a conservative one, as flattening must be more extreme for a cranium to be classified as deformed. In essence, the conservative nature of the function means that although artificially deformed crania may occasionally score as undeformed, undeformed crania should never bave a positive function score. Results of the discriminant function analysis are summarised in Table 1; raw data, including the full suite of measurements, are available upon request from the corresponding author (JLC).

For the 37 crania categorised as either undeformed or deformed, the function showed a $91.9 \%$ agreement with the visual classification. The nature of the section point meant that crania classified as undeformed were identified as such with $100 \%$ accuracy. Deformed crania were correctly classified in $76.9 \%$ of cases; given

Int. J. Osteoarchaeol. 17: 596-607 (2007)

DOI: $10.1002 /$ oa 
Table 1. Summarised results of discriminant function analysis

\begin{tabular}{lcccc}
\hline Visual classification & \multicolumn{2}{c}{ Predicted group membership* } & & Average function score \\
\cline { 2 - 3 } & Normal & Deformed & Total & \\
\hline Grouped cases & & & & \\
$\quad$ Undeformed & 24 & 0 & 13 & -4.4826 \\
$\quad$ Deformed & 3 & 10 & 14 & 1.6133 \\
Ungrouped cases & 14 & 0 & 10 & -3.3274 \\
$\quad$ Round frontal/flat occipital & 8 & 2 & -2.0000 \\
$\quad$ Ambiguous & & & & \\
\hline
\end{tabular}

* $91.9 \%$ of grouped cases correctly classified.

the conservative nature of the function, this was not unexpected and was considered to be an acceptable result. When applied to the crania of ambiguous deformation status, and again considering the conservative nature of the function, it seems reasonable to accept that those crania with positive function scores (accounting for 20\% of that category) are, in fact, deformed. Finally, given that $100 \%$ of the crania displaying round frontals and flattened occipitals scored as undeformed, it would appear that the function will not identify practices such as forms of cradleboarding in which the frontal is not involved.

\section{Testing the function}

Because the discriminant function was developed based on parameters that may vary among populations, we were uncertain as to whether or not the function would be applicable to other samples outside of the Philippines. However, given that the effects of artificial cranial deformation on vault contours appear to be reasonably universal, it was expected that this function would be applicable beyond the sample for which it was developed. In order to test its utility on other populations, a double-blind test was conducted by one of us (SCA) not involved in development of the original function. She applied the function to a comparative sample of 272 crania, including specimens she identified as deformed and undeformed from North and South America, and undeformed crania from Australia (Table 2). The sample of deformed crania included examples of both fronto-occipital and annular deformation. Results are presented in Table 3.

The function agreed with Antón's visual classification in $89.7 \%$ of cases. This is a significant result as the function was only slightly less accurate when applied to this diverse sample as when applied to the population for which it was developed. However, the true strength of the function becomes clear when the results are broken down by deformation status. While the function correctly predicted the group membership of deformed crania $73.7 \%$ of the

Table 2. Sample utilised for blind test of the function

\begin{tabular}{lr}
\hline Sample & $n$ \\
\hline Modern Caucasian & 8 \\
South America: Bolivia, Chile, Peru, Patagonia & 104 \\
North America: Southeast and Pacific Northwest & 40 \\
Australia & 120 \\
Total & 272 \\
\hline
\end{tabular}

Table 3. Summarised results of blind test

\begin{tabular}{lrrrr}
\hline Visual classification & \multicolumn{3}{c}{ Predicted group membership* } & Average function score \\
\cline { 2 - 4 } & Normal & Deformed & Total & \\
\hline Grouped cases & & & & -5.8736 \\
Undeformed & 171 & 2 & 99 & 2.1087 \\
Deformed & 26 & 73 & 99 & \\
\hline
\end{tabular}

* $89.7 \%$ of grouped cases correctly classified. 
time, undeformed crania were correctly classified in $98.8 \%$ of cases. Given the conservative nature of the function, the lower rate of success in the identification of deformed crania is in line with our expectations. It is worth noting that among this sample, deformation type had little effect on success of the function, with $74.1 \%$ of annular and $73.6 \%$ of fronto-occipitally deformed crania correctly identified as such. However, it is the remarkable success of the function in the correct classification of undeformed crania that most clearly demonstrates the broader utility of the function, in that a positive function score can be taken as strong evidence of deformation.

\section{An application}

Although not designed to take the place of visual classification among samples showing deformed and undeformed crania, the function serves to provide confirmation of visual classification and to aid in the classification of ambiguous crania. It also provides a means of assessing the deformation status of isolated archaeological or palaeontological specimens for which comparative samples are unavailable. Unfortunately, archaeological specimens that have been proposed to represent early cases of cranial deformation, including Shanidar 5 (Trinkaus, 1982) and Zhoukoudian Upper Cave 102 (Brothwell, 1975), are either incomplete or have significant post-depositional damage, meaning that the appropriate measurements cannot be taken. However, the application of our discriminant function to a small sample of fossil specimens for which measurements were available (Table 4) indicates that, in agreement with Brown (1981), at least one early Australian fossil (Kow Swamp 5) is artificially deformed. In contrast, although Trinkaus (1982) argued that Shanidar 1 was artificially deformed, it did not score as such under our function.

We also examined whether some Australasian fossils might be classified as deformed as a result of their low, flat foreheads. Our analysis of a sample of Indonesian hominids from Ngangdong suggests that the recessed frontal region of these specimens was a natural phenomenon, as all of the Ngangdong crania displayed negative function
Table 4. Function scores of select fossil crania

\begin{tabular}{lc}
\hline Specimen & Function score \\
\hline Keilor 1 & -6.7074 \\
Kow Swamp 1 & -4.7594 \\
Kow Swamp 5 & $0.968^{*}$ \\
Mungo 3 & -8.4139 \\
Ngandong 1 & -14.7688 \\
Ngandong 5 & -17.9024 \\
Ngandong 6 & -12.4581 \\
Ngandong 10 & -17.8378 \\
Ngandong 9 & -13.6814 \\
Shanidar 1 & -5.467 \\
\hline
\end{tabular}

* Deformed.

scores (Table 4). However, among the early Australian crania for which measurements were available, one (Kow Swamp 5) did score as deformed. Thus, it would appear that the cranial shape of this specimen was the result of artificial and not natural causes. These results provide further support for the argument that deformation is present in some specimens in the early Australian sample, and, as such, it is not appropriate to use cranial characteristics 'shared' between Indonesian hominids and early Australians with evidence of deformation to infer linkages between the two populations.

\section{Conclusion}

In most anthropological considerations of cranial deformation, classification of deformed and undeformed crania is only a first step, but it is a critical one because it defines the groups that will form the basis of subsequent analysis. Methods of classification need to be made more transparent; one of the primary benefits of the methodology described here is that it is easily replicated. Seriation based on degree of frontal and occipital flattening can assist in visual classification, particularly in samples in which there is a continuum from undeformed to severely deformed crania. Visual classification of the Philippine sample resulted in the division of the crania into four groups, including crania of ambiguous deformation status and those with round frontals and flat occipitals. Curvature indices for the frontal, parietals and occipital were chosen as discriminating variables because it

Int. J. Osteoarchaeol. 17: 596-607 (2007)

DOI: $10.1002 /$ oa 
has been documented that both of the major deformation types result in flattened frontal and occipital regions and in more angulated parietals; these indices have the additional benefit of requiring only six simple arc and chord measurements. The resulting function was tailored to be conservative, such that deformed crania may occasionally score as undeformed, but undeformed crania should never score as deformed. The function showed a $91.9 \%$ agreement with visual classification, with $100 \%$ of undeformed crania and $76.9 \%$ of deformed crania being correctly classified. When applied to the rest of the sample, $20 \%$ of ambiguous crania were identified as deformed, but all of the specimens showing round frontals and flat occipitals scored as undeformed. This indicates that the function will not identify practices such as cradleboarding where the frontal is not affected. A double-blind test was conducted in order to evaluate the broader utility of the function; when applied to a sample of 272 deformed and undeformed crania from a broad geographical and temporal range, the function agreed with visual classification in $89.7 \%$ of all cases. These results demonstrate the efficacy of the function, highlighting its utility for the identification of artificially deformed crania from a variety of contexts.

\section{Acknowledgements}

We would like to thank Carla Sinopoli for providing the base map, and John Speth, Jerry DeSilva and two anonymous reviewers for providing helpful comments on earlier drafts. Any mistakes that remain are, of course, our own. Research by JLC was supported by a National Science Foundation Graduate Research Fellowship.

\section{References}

Antón SC. 1989. Intentional cranial vault deformation and induced changes of the cranial base and face. American Journal of Physical Antbropology 79: 253267.

Antón SC, Jaslow CR, Swartz SM. 1992. Sutural complexity in artificially deformed human crania. Journal of Morphology 214: 321-332.

Copyright (C) 2007 John Wiley \& Sons, Ltd.
Antón SC, Weinstein KJ. 1999. Artificial cranial deformation and fossil Australians revisited. Journal of Human Evolution 36: 195-209.

Bacus E. 1995. Political economy and interaction: late prebistoric polities in the central Pbilippine Islands. Unpublisheds PhD thesis: University of Michigan.

Blackwood B, Danby PM. 1955. A study of artificial cranial deformation in New Britain. Journal of the Royal Antbropological Institute of Great Britain and Ireland 85: 173-191.

Brothwell D. 1975. Possible evidence of a cultural practice affecting head growth in some late Pleistocene East Asian and Australasian populations. Journal of Archaeological Science 2: 75-77.

Brown P. 1981. Artificial cranial deformation: a component in the variation in Pleistocene Australian Aboriginal crania. Archaeology in Oceania 16: 156-167.

Cheverud JM, Kohn LAP, Konigsberg LW, Leigh SR. 1992. Effects of fronto-occipital artificial cranial vault modification on the cranial base and face. American Journal of Physical Antbropology 88: 323-345.

Dean VL. 1995. Effects of Cultural Cranial Deformation and Craniosynostosis on Cranial Venous Sinus and Middle Meningeal Vessel Pattern Expression. Unpublished PhD thesis: Indiana University.

Dingwall EJ. 1931. Artificial Cranial Deformation: A Contribution to the Study of Ethnic Mutilation. John Bale, Sons and Danielson, Ltd.: London.

Friess M, Baylac M. 2003. Exploring artificial cranial deformation using elliptic Fourier analysis of procrustes aligned outlines. American Journal of Pbysical Antbropology 122: 11-22.

Gerszten P. 1993. An investigation into the practice of cranial deformation among the Pre-Columbian peoples of northern Chile. International Journal of Osteoarchaeology 3: 87-98.

Gill GW. 1998. Craniofacial criteria in the skeletal attribution of race. In Forensic Osteology: Advances in the Identification of Human Remains ( $2^{\text {nd }}$ edn), Reichs KJ (ed.). CC. Thomas Publishers Ltd: Springfield, IL; 293-317.

Goldstein MS. 1940. Cranial deformation among Texas Indians. American Journal of Pbysical Antbropology 27: 312-313.

Guthe CE. 1927. The University of Michigan Philippine Expedition. American Antbropologist 29: 69-76.

Guthe CE. 1929. Distribution of sites visited by the University of Michigan Philippine Expedition 1922-1925. Papers of the Michigan Academy of Science, Arts, and Letters 10: 79-89.

Hoshower LM, Buikstra JE, Goldstein PS, Webster AD. 1995. Artificial cranial deformation at the Omo M10 site: A Tiwanaku complex from the Moquegua Valley, Peru. Latin American Antiquity 6: 145-164.

Int. J. Osteoarchaeol. 17: 596-607 (2007)

DOI: $10.1002 /$ oa 
Moss ML. 1958. The pathogenesis of artificial cranial deformation. American Journal of Physical Antbropology 16: 269-286.

O'Loughlin VD. 2004. Effects of different kinds of cranial deformation in the incidence of wormian bones. American Journal of Physical Antbropology 123 : 146-155.

Ortner DJ. 2003. Identification of Pathological Conditions in Human Skeletal Remains. Academic Press: New York.
Trinkaus E. 1982. Artificial cranial deformation in the Shanidar 1 and 5 Neandertals. Current Antbropology 23: 198-199.

Watson JT. 1999. A Quantitative Study of Artificial Cranial Deformation: Bio-cultural Behavior in Southwest Prebistory. Unpublished MA thesis: Wichita State University.

White CD. 1996. Sutural effects of fronto-occipital cranial modification. American Journal of Pbysical Antbropology 100: 397-410. 